\title{
Experimental and Numerical Study on Performance of Concrete Slabs Subjected to Severe Fire
}

\author{
FARIS ALI ${ }^{1}$, ALI NADJAI ${ }^{1}$, and ABID ABU-TAIR ${ }^{2}$ \\ 1- FireSERT, University of Ulster, Shore Road, Jordanstown, BT37 OQB, UK. \\ 2- Civil Engineering Department, Al-Quds University, Israel.
}

\begin{abstract}
:
The first part of this paper represents an experimental investigation on explosive spalling and deformation of 6 full-scale simply supported reinforced concrete slabs subjected to conventional fire curve (BS476) and severe hydrocarbon fire curve, performed at the Fire Research Centre, University of Ulster, UK. Each slab was loaded with $65 \%$ of its BS8110 design load and was heated from the bottom side only. Temperature profile was recorded at 3 depths within the slabs and the moisture content was also measured before and after the tests. The deflection of the slabs was recorded at the middle of the 3 meters span. The second part of the paper represents a Finite Element Modelling of the slabs using DIANA software. The concrete slabs were modelled including the embedded reinforcement to conduct a non-linear transient structural analysis taking into account cracks appearance and creep. A comparison between the experimental and the FEM results is presented in the paper.
\end{abstract}

KEYWORDS: concrete, slab, fire, explosive spalling, finite element, hydrocarbon fire, diana.

\section{NOMENCLATURE LISTING}

$\begin{array}{llll}{[k]} & \text { element heat conduction/convection matrix } & \mathrm{K}] & \text { material stiffness matrix } \\ {[c]} & \text { element heat capacity } & \text { Greek } & \\ {\left[T_{n}\right]} & \text { element nodal temperature vector } & \sigma & \text { Stefan-Boltzmann coefficient } \\ {[F]} & \text { element nodal heat input vector } & \{\varepsilon\} & \text { strain vector } \\ T_{e} & \text { temperature of emitting surface } & \left\{\varepsilon_{T}\right\} & \text { vector of the temperature related total } \\ T_{r} & \text { temperature of surface } & \{\sigma\} & \text { stress vector } \\ l_{l} & \text { direction cosine of } \mathrm{n} \text { relative to } \mathrm{x}=\cos \theta & \varepsilon_{e} & \text { emissivity of the surface } \\ m_{l} & \text { direction cosine of n relative to } \mathrm{y}=\sin \theta & \varepsilon_{t h} & \text { thermal strain } \\ k & \text { coefficient of thermal conductivity } & \varepsilon_{c r} & \text { creep strain } \\ H & \text { coefficient of heat transfer } & \varepsilon_{t r} & \text { transient creep strain }\end{array}$

\section{INTRODUCTION}

The majority of the research studies on behaviour of concrete elements performed in the last decades have mainly focused on beams and columns. Some of these studies investigated small scale slabs (El-Hawary, et. al. [7], Shuttleworth [14]), but a very small number of investigations have involved large scale specimens. Most of these slabs were tested under standard normal heating rates BS476 or ASTME119 (Shirly et. al. [13]). However, the effect of more severe fires (hydrocarbon fire curve for example) on the performance of structural elements is gathering momentum following the tragic events of 9/11 in New York. The research performed in the BRE (Cooke [5]) is among the rare works, which involved the effect of hydrocarbon curve on the fire resistance and deflection of concrete slabs. However, no explosive spalling of concrete was reported in this study. Previous research (Ali. et.al. [1], Gamal et.al.[9], Selih, et.al. [12], Chung et.al. [4] and others) has shown that the probability of explosive spalling of concrete increases under higher heating rates. It is well established now that heating a concrete element from one side creates two moving fronts: heat and moisture front. The two fronts move away from the heated face of the concrete towards the cold unheated side. The speed of the two fronts depends on several factors including the heating rate where the two fronts could meet at a specific distance inside the concrete. This causes the water within the moisture clog to transform to vapour. The build up of high vapour pressure which may reach 3 to 5MPa [4] can cause explosions in the concrete. In addition, recent research suggests that the presence of steel reinforcement impedes moisture movement and produces quasi-saturated moisture clog zones that could lead to the development of significant pore pressure [4]. 
The objective of this paper is to represent the outcomes of an experimental study performed on 6 large simply supported concrete slabs $3300 \times 1200 \times 200 \mathrm{~mm}$. The slabs were subjected to conventional (BS476) and hydrocarbon heating rates. The temperatures were measured inside the slabs at three depths: - surface, $40 \mathrm{~mm}$ (steel reinforcement), and $100 \mathrm{~mm}$. The measured mid-span deflection of the concrete slabs is also presented. The explosive spalling observed during the tests and an assessment criterion of spalling are discussed. The paper represents also a Finite Element Modelling of the slabs using DIANA software. The concrete slabs were modelled including the embedded reinforcement to conduct a non-linear transient structural analysis taking into account cracks appearance and creep. A comparison between the experimental and the FEM results is presented in the paper.

\section{THE EXPERIMENTAL PROGRAMME}

The experimental work involved testing 6 large scale 3300x1200x200mm normal strength reinforced concrete slabs with an average concrete strength of $42 \mathrm{~N} / \mathrm{mm}^{2}$ at 28 days. During the tests the concrete slabs were mounted on the top of the furnace with clear span of $3000 \mathrm{~mm}$ (see Fig. 1). Each slab was reinforced with 6 T12 steel bars, embedded longitudinally along the slab at a spacing of 220 mm centre to centre, as illustrated in Fig. 1. Secondary reinforcement comprising of 13 T10 steel bars were placed perpendicular to the main reinforcement at a spacing of $300 \mathrm{~mm} \mathrm{c} / \mathrm{c}$. The concrete cover of the steel reinforcement was $40 \mathrm{~mm}$ vertically and $50 \mathrm{~mm}$ on slab sides (see Fig. 1).

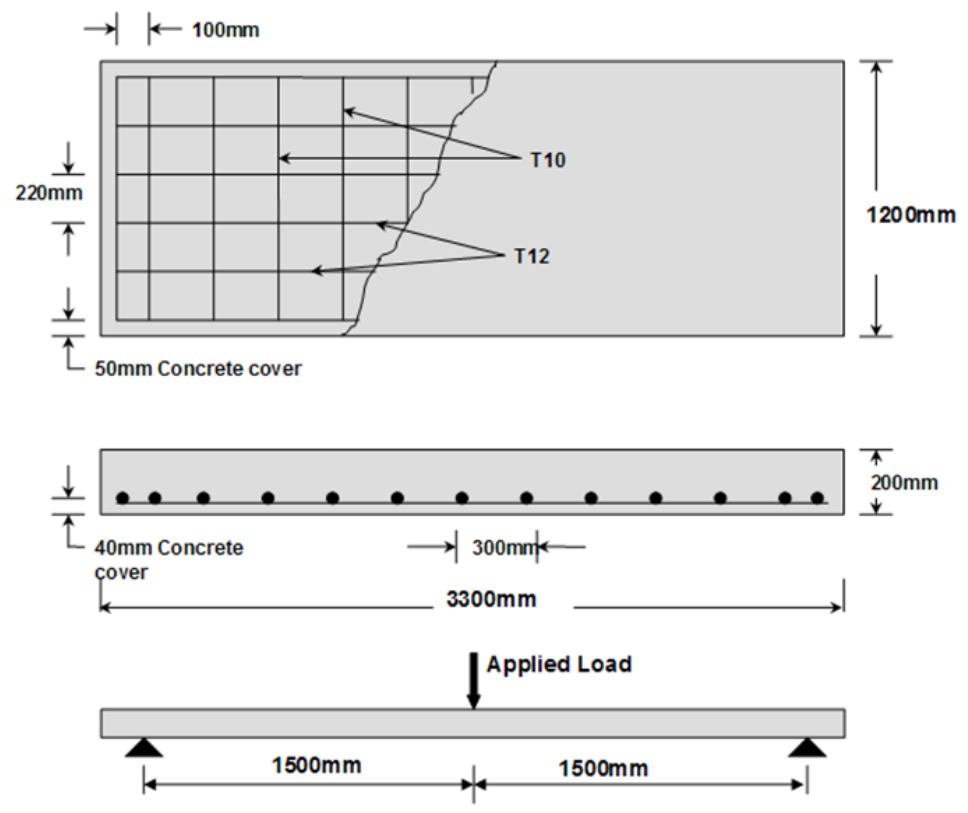

Fig. 1. Loading and reinforcment details of concrete slabs

\section{Test Parameters}

All the simply supported slabs were tested under the same loading level (including self weight $)=0.65(27 \mathrm{kN})$ of the design load of BS8110. This load was applied at the mid-span point of each slab as shown in Fig. 1. Two heating regimes were used during the experimental programme, BS476 and hydrocarbon fire curves. Fig. 2 shows the

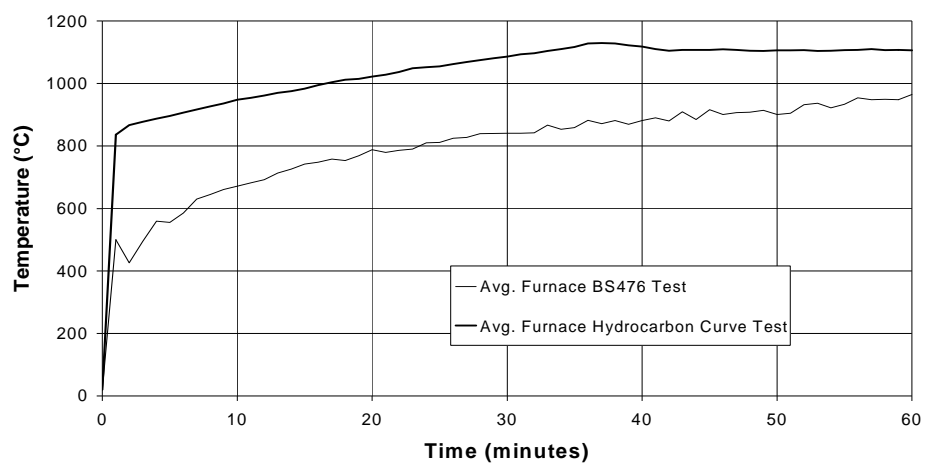

Fig. 2. Average temperatures recorded in the furnace 
average experimental fire curves achieved during the tests. Three slabs S1, S2 and S3 were tested using the standard temperature-time curve BS 476 (ISO834), while the remaining slabs S4, S5 and S6 were tested under the severe hydrocarbon fire curve (see Table 1). All the tests were performed in a $4 \times 3 \times 3 \mathrm{~m}$ combustion chamber, with the slab specimen situated on top of the furnace and heated from beneath.

\section{Experimental Data Measurement}

In order to measure the temperature distribution within the specimens, each slab was fitted with five $1.5 \mathrm{~mm}$ sheathed thermocouples. Three of the thermocouples were used to measure the bottom surface temperature (one located at the mid span of the slab and the other two were located $400 \mathrm{~mm}$ from both supported ends of the slab). The remaining two thermocouples were cast within the slab. The first one was located at the centre of the slab, while the second was touching the $7^{\text {th }}$ reinforcement bar (mid-span of the slab) at a depth of approximately $40 \mathrm{~mm}$ from the bottom of the slab surface. Slab deflection was measured using a Linear Variable Differential Transformer (LVDT), located at the mid span of the slab. Temperature distribution and slab deflection data was recorded using a data logging system. The moisture content was measured on both of the top and the bottom surfaces of each slab using Tramex CRH concrete moisture content measuring device. These measurements were then repeated in the same locations following the test process. Audio and visual observations of explosive spalling were made during the tests through the quartz windows situated in the door of the combustion chamber.

\section{Test Methodology}

The slabs were set on top of the combustion chamber and the necessary measuring devices were attached. The load was applied at a constant rate until the desired loading level was reached. Then the combustion chamber burners were ignited and controlled to achieve the required time-temperature curve. The applied load was kept at a constant level throughout the test. The duration of each test was 60 minutes.

\section{Spalling Assessment}

The primary criterion used to assess spalling was the degree of spalling. Following the test, the concrete lost due to spalling was collected and weighed. The degree of spalling $\left(\mathbf{S}_{\mathbf{d}}\right)$ was then measured using the following formula:

$\mathrm{S}_{\mathrm{d}}=\mathrm{W}_{\mathrm{L}} / \mathrm{W}_{\mathrm{C}}$

Where: $\mathbf{W}_{\mathbf{L}}$ is the weight of concrete lost due to explosive spalling and $\mathbf{W}_{\mathbf{C}}$ is the weight of the concrete slab before testing. The depth of spalling and percentage surface area lost due to explosive spalling were approximately measured after the test. This enabled to estimate the volume of concrete that has disintegrated from the slab due to explosive spalling.

\section{TESTS RESULTS}

The main results from the series of experiments undertaken are shown in Table 1. All slabs were subjected to the same loading level (including self weight) $=0.65$ of the design load of BS8110 represented in one concentrated load of $27 \mathrm{kN}$ at mid span of the slab as shown in Fig. 1. All of the six slabs experienced explosive spalling during testing, with more violent spalling of slabs exposed to the hydrocarbon fire curve where spalling started after 2 minutes of heating. Slabs subjected to the BS476 fire curve did not experience explosive spalling until the $15^{\text {th }}$ minute of heating.

\section{Slabs Tested Under BS476 (ISO834) Fire Curve}

\section{Explosive Spalling}

All slabs have experienced explosive spalling. The spalling was violent with distinctive noises. Fig. 3 shows the extent of spalling of the three slabs S1, S2 and S3. The degree of spalling experienced by slabs S1-S3 is presented in Table 1. The degree of spalling of the three slabs was reasonably close to each other.The depth of the spalled areas varied along the surface of the slabs, with the greater depths noted towards both ends of the slabs. Slab S2 experienced the largest degree of spalling at 2.7\%; with a maximum spalling depth of 25mm. Slabs S1 and S3 had maximum spalling depth of 20mm and 15mm respectively. 
Table 1. Tests results

\begin{tabular}{|l|c|c|c|c|c|}
\hline $\begin{array}{l}\text { Fire } \\
\text { Curve }\end{array}$ & \multirow{2}{*}{$\begin{array}{l}\text { Slab } \\
\text { Ref. }\end{array}$} & $\begin{array}{l}\text { Spalling } \\
\text { Degree }\end{array}$ & \multicolumn{2}{|c|}{$\begin{array}{c}\text { Moisture Content } \\
\text { before heating } \\
\text { \% }\end{array}$} & $\begin{array}{c}\text { Max. } \\
\text { Deflection }\end{array}$ \\
\cline { 3 - 6 } & & $\%$ & Top & Bottom & $\mathrm{mm}$ \\
\hline \multirow{4}{*}{ BS476 } & S1 & 1.0 & 3.6 & 5.5 & 29.7 \\
\cline { 2 - 6 } & $\mathrm{S} 2$ & 2.7 & 3.7 & 5.7 & 32.1 \\
\cline { 2 - 6 } & $\mathrm{S} 3$ & 2.2 & 3.9 & 6.0 & 34.2 \\
\hline \multirow{3}{*}{ Hydrocarbon } & $\mathrm{S} 4$ & 2.1 & 3.7 & 5.2 & 44.8 \\
\cline { 2 - 6 } & $\mathrm{S} 5$ & 4.3 & 3.8 & 4.9 & 44.7 \\
\cline { 2 - 6 } & $\mathrm{S} 6$ & 3.2 & 3.5 & 4.8 & 43.9 \\
\hline
\end{tabular}

The first occurrence of explosive spalling was observed approximately after 15 minutes at a slab surface temperature around $750^{\circ} \mathrm{C}$. This explosive spalling phase lasted for approximately 20 minutes, after which only minor isolated incidents of explosive spalling were noted.

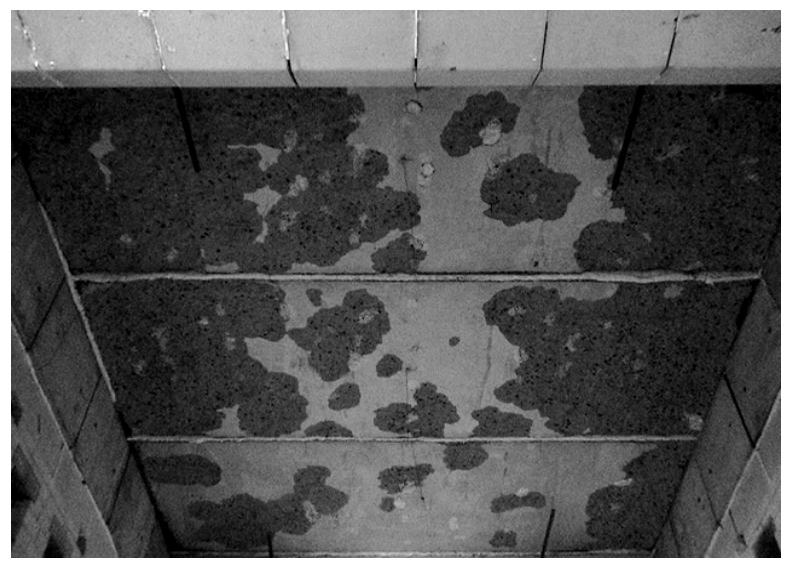

Fig. 3. Explosive spalling of slabs S1-S3 (bottom heated surface)

\section{Temperature Profile along Slab Thickness}

A significant temperature gradient was recorded along the slab thickness during heating. Fig. 4 shows the development of temperature of slab S2 at three points:- surface, at reinforcement level and at the mid height of the slab. Fig. 4 clearly shows a high thermal gradient of around $880^{\circ} \mathrm{C}$ between the surface and the center of the slab. It is important to note that slab S2 has experienced the highest degree of spalling when subjected to the BS476 fire curve. Due to violent explosive spalling, the surface thermocouple of slab S1 has dislodged from the slab surface between the $25^{\text {th }}$ and $26^{\text {th }}$ minute. For this reason the surface temperature recorded after the $25^{\text {th }}$ minutes for slab S1 are disregarded in this analysis. All slabs showed a similar temperature development, with slab S2 achieving a slightly higher maximum temperature of $138^{\circ} \mathrm{C}$ after 60 minutes. The thermocouple utilized to measure the temperature at the steel reinforcement is situated at a depth of $40 \mathrm{~mm}$ from the exposed surface of the concrete slab.

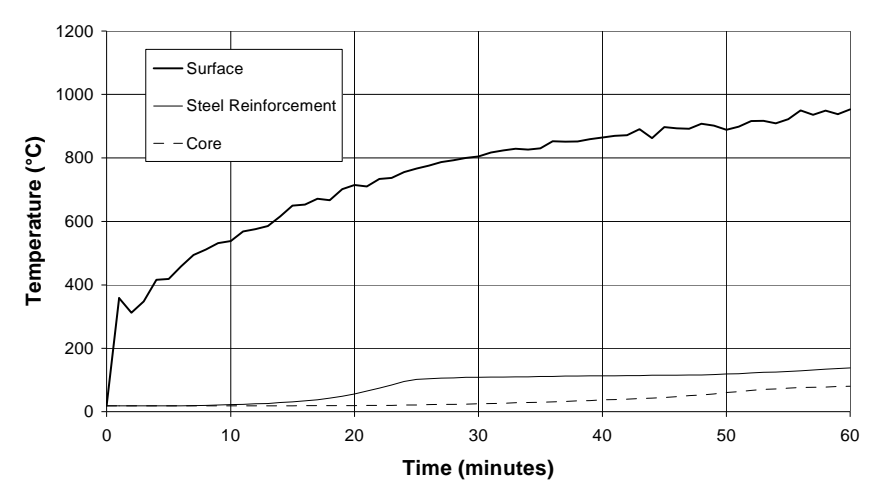

Fig. 4. Temperature development within slab S2 


\section{Slab Deflection}

Slab deflection was measured at the central point of the span. Fig. 5 shows the development of the deflection of slabs S1, S2 and S3 subjected to BS476 fire curve. It can be seen from Fig. 5 that the three slabs have experienced reasonably similar rates and values of deflection (Table 1). From Fig. 5 it can also be seen that slab's deflection is relatively small, up to a temperature of approximately $450^{\circ} \mathrm{C}$. Beyond this temperature the deflection increases at higher rate up to a temperature of approximately $800^{\circ} \mathrm{C}$. After that the rate of deflection increases again until the end of the test. This increase appears to coincide with the onset of severe explosive spalling and the reduction in the slabs cross section. In general, slabs have achieved an average maximum displacement of $32 \mathrm{~mm}$ at a furnace temperature approaching $965^{\circ} \mathrm{C}$, with slab S3 showing a marginally greater maximum deflection of $34.2 \mathrm{~mm}$.

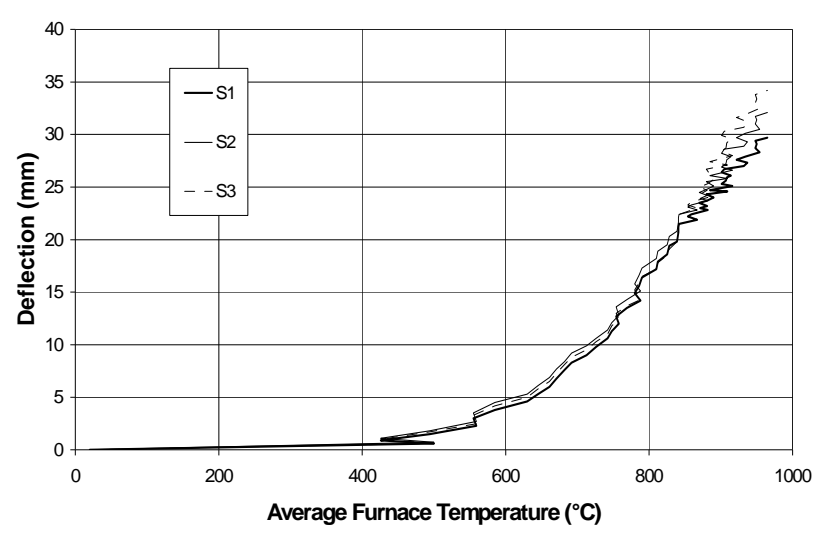

Fig. 5. Deflection recorded for slabs S1-S3

\section{Slabs Tested Under Hydrocarbon Fire Curve}

\section{Explosive Spalling}

In an apparent difference from BS476, slabs tested under Hydrocarbon fire have experienced more violent explosive spalling which happened on noticeably early time, after 2 minutes of the start of the test. The degree of spalling experienced by slabs S4-S6 is presented in Table 1. Slab S5 experienced the highest degree of spalling of $4.3 \%$ with a maximum spalling depth of $20 \mathrm{~mm}$. Slabs S4 and S6 both have a maximum spalling depth of approximately $15 \mathrm{~mm}$. Also it is important to emphasis that most of the violent explosive spalling occurred within the first 12 minutes. After that only occasional occurrences of mild spalling were noted.

\section{Temperature Profile along Slab Thickness}

As expected, the temperature gradient in slabs subjected to hydrocarbon fire was more evident and higher in values $\left(1020^{\circ} \mathrm{C}\right)$. In particular Fig. 6 presents the temperature profile of slab S5, which has experienced a degree of spalling of $4.3 \%$ (Table 1). From Fig. 6, it can be seen that a similar temperature gradient exists within slab S5 to that of slab S2 tested under the BS476 curve. However, the temperatures recorded within slab S5 are higher which indicates the increased severity of the hydrocarbon fire curve. After 30 minutes of fire exposure, the surface of slab S5 has reached a temperature of approximately $1100^{\circ} \mathrm{C}$, while temperature at the steel reinforcement was approximately $130^{\circ} \mathrm{C}$. Even the centre of the slab has experienced a slight temperature increase to $50^{\circ} \mathrm{C}$ only. All three slabs showed a very similar temperature profile to that of the hydrocarbon fire curve displayed in Fig. 2, reaching a maximum temperature of approximately $1100^{\circ} \mathrm{C}$ after 60 minutes. Figure 6 does not only highlight the large temperature gradient that exists in normal strength concrete but also underline the enhanced temperature profile experienced by normal strength concrete when exposed to hydrocarbon fire conditions as

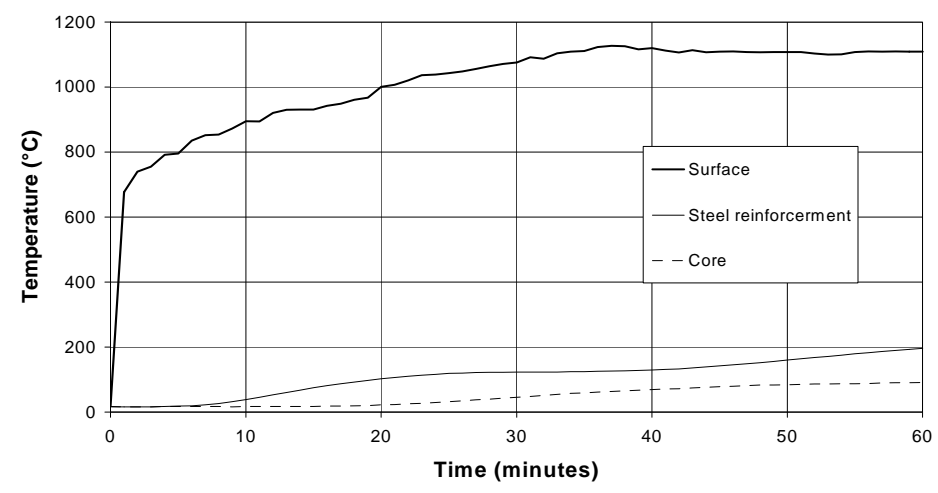

Fig. 6. Temperature development within slab S5. 
opposed to the conventional BS476 time-temperature curve.

\section{Slab Deflection}

Figure 7 shows the development of the deflection of slabs S4-S6 when exposed to the hydrocarbon fire curve. All 3 slabs showed almost identical rates of deflection. Initially the slabs deformed at gradual rate, until a temperature of approximately $840^{\circ} \mathrm{C}$ was reached after 2 minutes. At this point, the gradient of the curves in Fig. 7 shows a sudden and sharp increase, indicating a rapid increase in the deflection of the slabs. This point coincides with the moment when explosive spalling has started and caused a reduction in the slab cross section. This increase continues for the remainder of the experiment, with the slabs achieving an average maximum displacement of $44.5 \mathrm{~mm}$ at a temperature approaching $1100^{\circ} \mathrm{C}$. Slab S4 displays the largest deflection of $44.8 \mathrm{~mm}$.

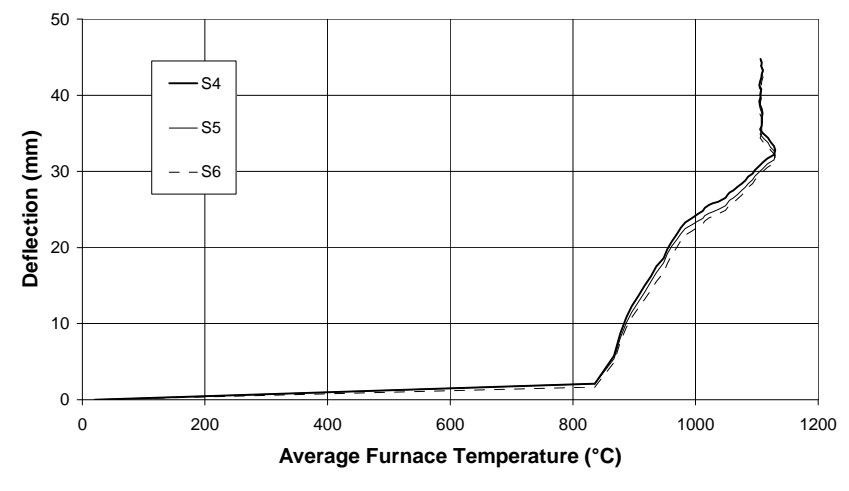

Fig. 7. Deflection recorded for slabs S4-S6.

\section{ANALYSIS OF RESULTS}

\section{Effect of fire severity on slab deflection}

From Fig. 8, it can be seen that all slabs showed a slow deformation rate during the early stages of fire exposure. After 2 minutes, at which point the slab deformation is almost negligible, the average furnace temperature under the BS476 and Hydrocarbon fire curves has reached approximately $450^{\circ} \mathrm{C}$ and $840^{\circ} \mathrm{C}$ respectively. At this stage, slabs subjected to both heating regimes showed a sudden and sharp increase in deflection, with the gradient of the curves in Fig. 8 indicating that the slabs exposed to the hydrocarbon fire experienced a more rapid rate of deflection. Under the BS476 curve, the slab deflection increases as the temperature in the furnace (and therefore the surface temperature of the concrete) continues to rise. However, it is noticeable that even when the temperature of the hydrocarbon fire reaches a 'ceiling' of approximately $1100^{\circ} \mathrm{C}$, the slab deflection continues to increase. In summary, although both heating regimes appear to induce a similar rate of deflection on the concrete slabs, the faster temperature development of the hydrocarbon fire ensures that slabs exposed to the more severe fire conditions will experience a more rapid rate of deflection, and ultimately a greater deformation will be recorded for those slabs.

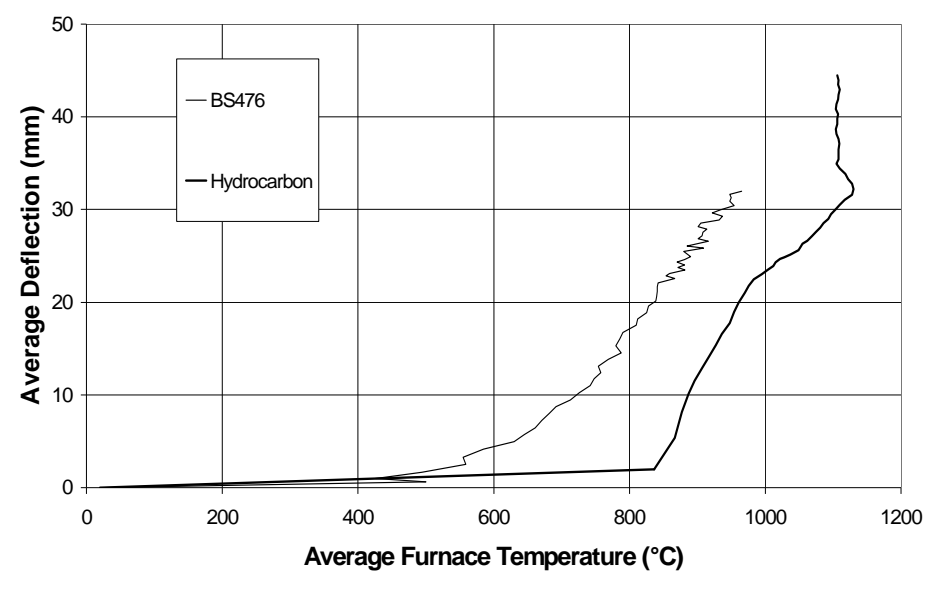

Fig. 8. Comparison of average deflections of slabs tested under BS476 and Hydrocarbon fire curves.

\section{Effect of Fire Severity on Explosive Spalling}

From Table 1, it can be seen that the specimens exposed to the hydrocarbon fire curve experienced a greater degree of explosive spalling. The maximum degree of spalling exhibited by slab S2 under the 
conventional BS476 fire curve was $2.7 \%$, whereas $4.3 \%$ of slab S5 was removed by explosive spalling when exposed to the hydrocarbon fire. Although the slabs subjected to the hydrocarbon fire curve exhibited the greater amount of spalling, the actual depth of the spalling was quite similar for all slabs, measuring between $15 \mathrm{~mm}$ and $25 \mathrm{~mm}$, regardless of the fire severity. To summarize the analysis, an increase in fire severity resulted in greater degree of explosive spalling. However, from the experiments undertaken, the depth of spalling was not noticeably affected by the increase in fire severity but the area affected by spalling was larger under the hydrocarbon fire curve.

\section{Evidence of Moisture Front Movement through Observation}

Observations were made of the moisture front movement of slab S6, which was exposed to the hydrocarbon fire curve. Prior to testing, the average moisture content of the slab was recorded both on the top surface of the slab and on the bottom surface (Table 1) exposed to the heating regime, with moisture content of $3.5 \%$ and $4.8 \%$ obtained for the respective surfaces. After 8 minutes of exposure to the hydrocarbon fire curve, water started to appear on the top (unheated) surface of the slab at the four lifting hooks (embedded for slab lifting). As the temperature within the slab continues to rise throughout the test, the moisture is driven away from the advancing heat front towards the top surface. During the fire test and after 50 minutes, when even the slab core temperature was only $100^{\circ} \mathrm{C}$, large pools of expelled water were visible on the top (unheated) surface of the slab as shown in Fig. 9.

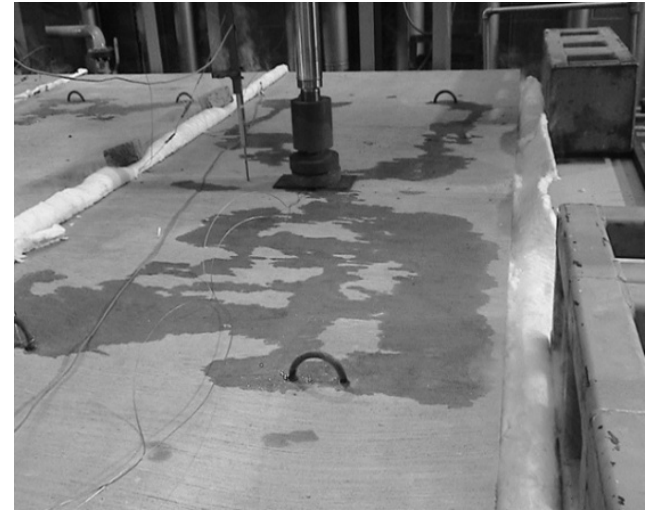

Fig. 9. Water pools emerging on the top surface of slab S6 at minute 50 during the test.

\section{FINITE ELEMENT MODELING}

The concrete slabs were modeled using the Finite Element Method based software DIANA [6]. A heat flow-stress 3D staggered model was adopted in order to perform a nonlinear heat and structural analysis. A 3D twenty node solid brick CHX60 [6] element was used to model the concrete slab body. However, in order to allow for transient heat analysis to be performed quadrilateral boundary 4 nodes BHQ4HT element was used to model the external flow film surrounding the slab. DIANA allows steel reinforcement bars to be included in the model as a part of the concrete slab. The meshed model consisted of 1372 element and 6896 nodes. The calculation phase was significantly affected by crack appearance influencing reaching a convergence in the iterative analysis. A trial and error approach was used to determine the appropriate iteration method of solving the equations. The Quasi-Newton method with line search algorithm was used as an iterative procedure to solve the equations and to obtain the required accuracy.

\section{Material Modeling}

In this study, the concrete was treated as orthotropic material after cracking and isotropic beforehand. A non-linear fracture mechanics with cracking was adopted in the analysis of the tensile behavior of concrete. An angel value of $60^{\circ}$ was used to allow the formation of non-orthogonal cracks in integration point. The cracking criterion shown in Fig. 10 and the smeared crack model with Moelands-Reinhardt tension softening curve shown in Fig. 11 were used in the analysis [6]. For concrete compressive behavior the nonlinear Thorenfeldt model was used. For steel reinforcement a standard stress strain curve was used and the Von Mises yield criterion was adopted in the model. The EC2 [8] parameters were used to model the nonlinear behavior of concrete and steel under high temperatures. 


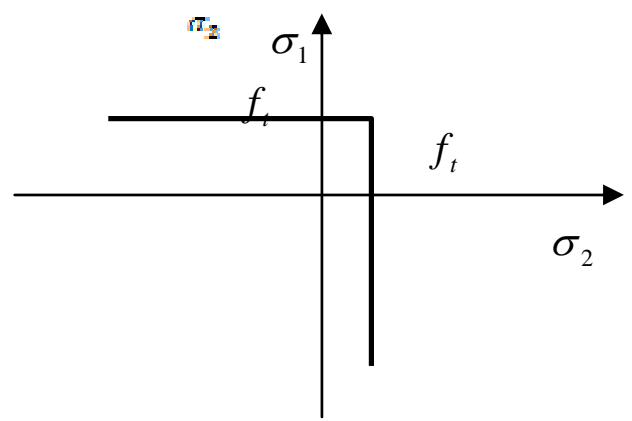

Fig. 10. Tension cut-off criterion used in the analysis.

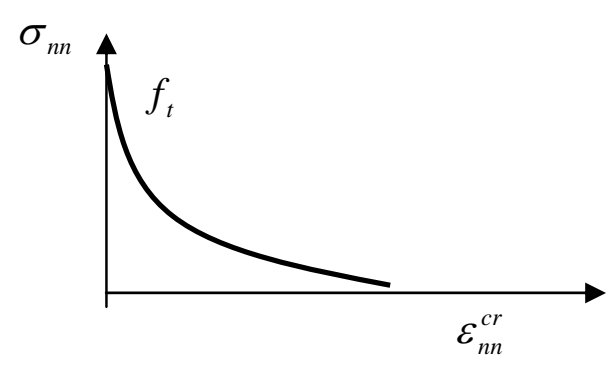

Fig. 11. Moelands-Reinhardt softening curve.

\section{Thermal Analysis}

At start a thermal analysis was performed to determine the nodal temperature using a stepwise heat transfer time-history taking into account conduction, convection and radiation effects. The finite element formulation is based on the Galerkin method [6] by determining $\{T\}$ as a function of time:

$$
[k]\left\{T_{n}\right\}+[c]\left\{\dot{T}_{n}\right\}=\left\{F_{n}\right\}
$$

Where:

$[k]=$ element heat conduction/convection matrix

$[c]=$ element heat capacity

$\left\{T_{n}\right\}=$ element nodal Temperature Vector

$\{F\}=$ element nodal heat input vector and is defined at boundary nodes using equation:

$-k\left[\frac{\partial T}{\partial x} l_{1}+\frac{\partial T}{\partial y} m_{1}\right]=h\left[T_{e}-T_{r}\right]+\varepsilon_{e} \sigma\left[T_{e}^{4}-T_{r}^{4}\right]$

Where: $T_{e}=$ temperature of emitting surface; $T_{r}=$ temperature of surface; $\sigma=$ Stefan-Boltzmann coefficient; $l_{1}$-direction cosine of $\mathrm{n}$ relative to $\mathrm{x}=\cos \theta ; m_{1}=$ direction cosine of $\mathrm{n}$ relative to $\mathrm{y}=\sin \theta ; \varepsilon_{e}=$ emissivity of the surface, $k=$ coefficient of thermal conductivity; $h=$ coefficient of heat transfer.

\section{Strain at elevated Temperatures}

The total deformation occurring in the concrete when subjected to high temperatures was calculated using the following relationship:

$\varepsilon_{T}=\varepsilon_{t h}+\varepsilon_{t r}$

Where:

$\varepsilon_{t h}=$ the thermal strain; $\varepsilon_{t r}=$ transient creep strain usually occurs under temperatures less than $550^{\circ} \mathrm{C}$ [ 3].

The Anderberg - Thelanderson model [2] was adopted to calculate the transient creep strain:

$\varepsilon_{t r}=-2.35 \frac{\sigma_{c}}{f_{c}} \varepsilon_{t h}$

Where: $\sigma_{c}=$ the concrete stress level; $f_{\mathrm{c}}=$ the concrete compressive strength.

\section{STRUCTURAL ANALYSIS}

After performing the transient heat analysis and the nodal temperature history curve is obtained, a nonlinear structural analysis was performed using the following governing equation: 
$\{\sigma\}=[K]\left\{\varepsilon-\varepsilon_{T}\right\}$

Where:

$[\sigma]=$ stress vector

$\{\varepsilon\}=$ the strain vector

$\left\{\varepsilon_{T}\right\}=$ vector of the temperature related total strain

$[\mathrm{K}]=$ the material stiffness matrix which is dependant on the non-linear analysis solution where the smeared crack model with tension softening model was adopted as mention before.

\section{Material properties used in the Analysis}

All the material properties used in the calculation (except the concrete compressive strength) were taken from various references [3]. Table 2 shows the material properties for both steel and concrete used in the tests. The change of the properties under high temperatures was also considered in calculation and taken from reference [8].

Table 2. Material properties used in the analysis.

\begin{tabular}{|l|l|l|l|l|l|l|}
\hline Material & $\begin{array}{l}\text { Compressive } \\
\text { strength } \\
\mathbf{N} / \mathbf{m m}^{\mathbf{2}}\end{array}$ & $\begin{array}{l}\text { Tensile } \\
\text { strength } \\
\mathbf{N} / \mathbf{m m}^{\mathbf{2}}\end{array}$ & $\begin{array}{l}\text { Thermal } \\
\text { Conductivity } \\
\mathbf{J} / \mathbf{m m} / \mathbf{m i n} / \mathbf{C}\end{array}$ & $\begin{array}{l}\text { Thermal } \\
\text { capacitance } \\
\mathbf{J} / \mathbf{k g} / \mathbf{C}\end{array}$ & $\begin{array}{l}\text { Coefficient } \\
\text { Of thermal } \\
\text { expansion }\end{array}$ & $\begin{array}{l}\text { Modulus } \\
\text { of } \\
\text { Elasticity } \\
\text { KN/mm }\end{array}$ \\
\hline Concrete & 42 & 4.1 & 0.1 & 1.8 & $12 \times 10^{-6}$ & 39.3 \\
\hline steel & - & 460 & 4.5 & - & $12 \times 10^{-6}$ & 210 \\
\hline
\end{tabular}

\section{Calculation Results}

The slab module was used to calculate the deflection and the temperatures profile across the depth of the slab. Two fire loads were used: the BS476 and the Hydrocarbon fire curves. The calculation phase was slow and was aborted many times as no convergence was reached. Therefore, the iteration method was changed until the Quasi-Newton with line-search algorithm was found to be appropriate.

\section{Results for slab subjected to BS476 (ISO 834)}

Figure 12 shows a curve representing the temperature progress with time at the bottom surface of the slab calculated using FEM. Figure 12 also represents the experimental curves of the temperature progress obtained from the 3 slabs S1, S2 and S3. The Figure shows that the slab model has produced lower temperature profile than the experimental. This can be attributed to the fact that the spalling that happened at early stages has disturbed the mechanism of heat flow particularly at the surface level. However, better agreement was obtained for temperature profiles at deeper levels at the reinforcement and middle height of the slab as shown in Fig. 13.

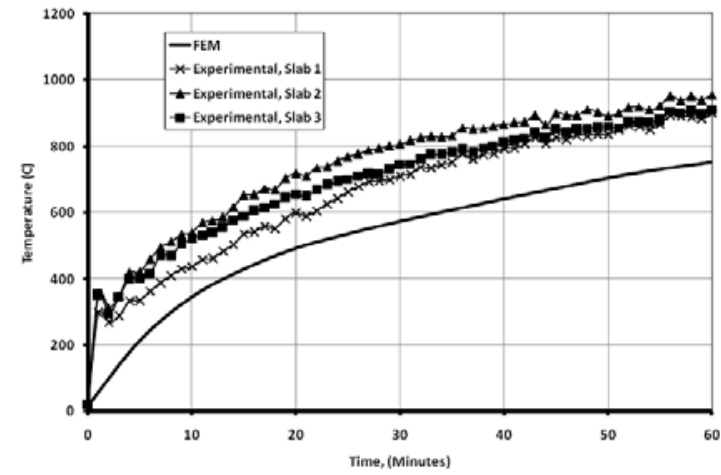

Fig. 12. Experimental and FEM temperatures at slabs surface under BS476

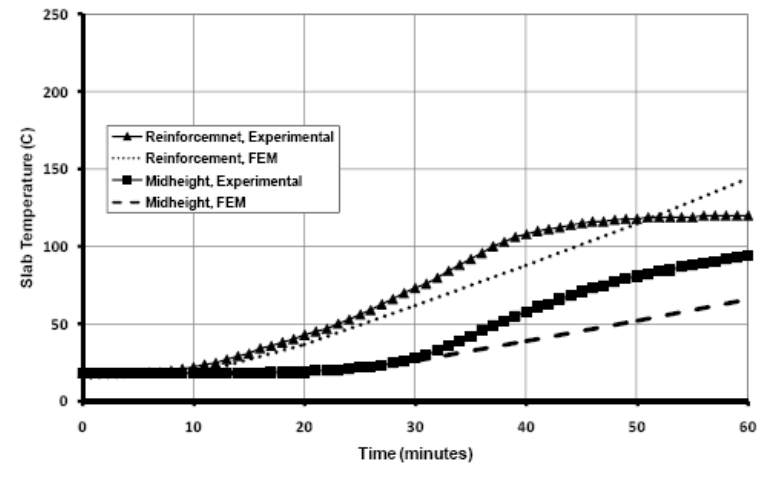

Fig. 13. Experimental and FEM temperatures tested at reinforcement \& mid depth of slabs under BS476 
Figure 14 shows the results of the deflection at the centre of the slab calculated using FEM compared with deflections obtained form the tests. The Figure shows a reasonable agreement in trend of the deflection development with time. However, the total value of deflection produced from the model is higher than the experimental. This may be attributed to the fact that many of the parameters used in the calculation were empirical particularly the cracking pattern and mechanism.

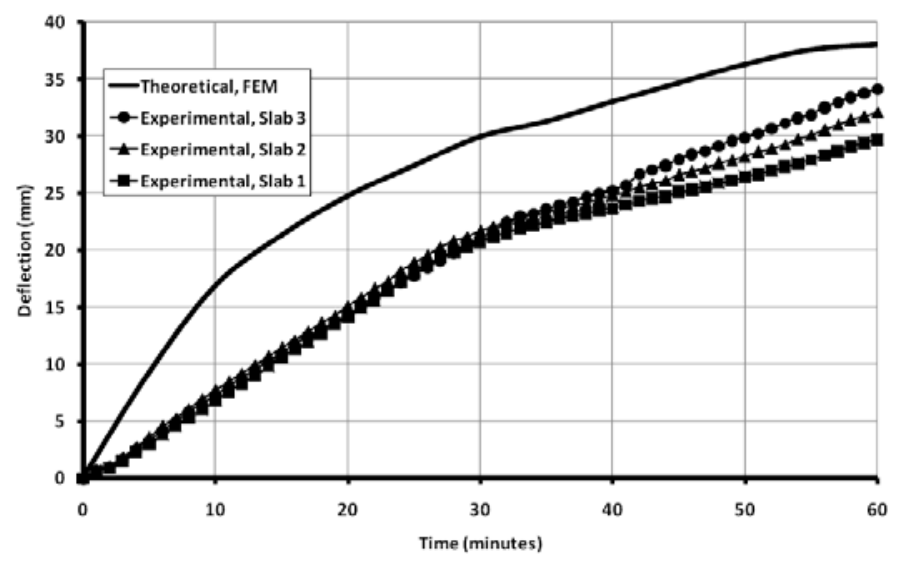

Fig. 14. Slab deflection obtained from BS476 tests and calculated using the FEM

\section{Results for slab subjected to the Hydrocarbon fire curve}

Figure 15 shows a curve representing the temperature progress with time at the bottom surface of the slab calculated using FEM. Figure 15 also represents the experimental curve of the temperature progress obtained from the test. The Figure shows that the slab model has produced lower temperature profile than the experimental. However, better agreement was obtained for temperature profiles at deeper levels at the reinforcement and middle height of the slab as shown in Fig. 16. This pattern is similar to the patteen obtained from slabs tested the BS476. Figure 17 shows the results of deflection calculated at the centre of the slab compared with deflections obtained form the tests. Figure 17 shows a reasonable agreement in trend of the deflection development with time. However, the total value of deflection produced from the model is higher than the experimental. This may be attributed to the absence of experimentally obtained values of many of the calculation parameters.

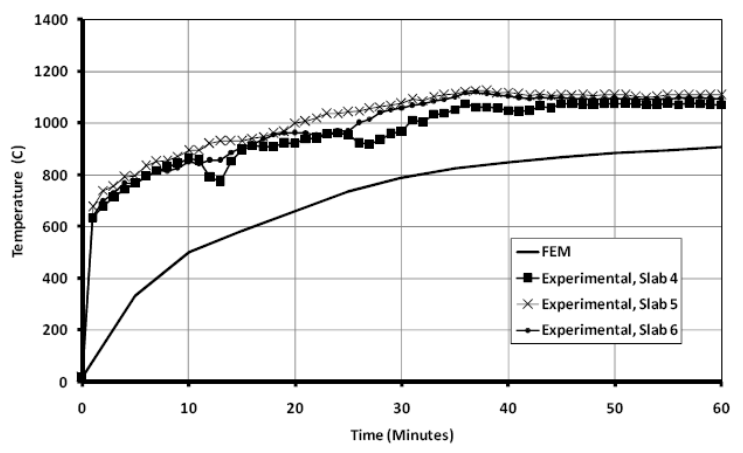

Fig. 15. Experimental and FEM temperatures at slabs surface under Hydrocarbon curve

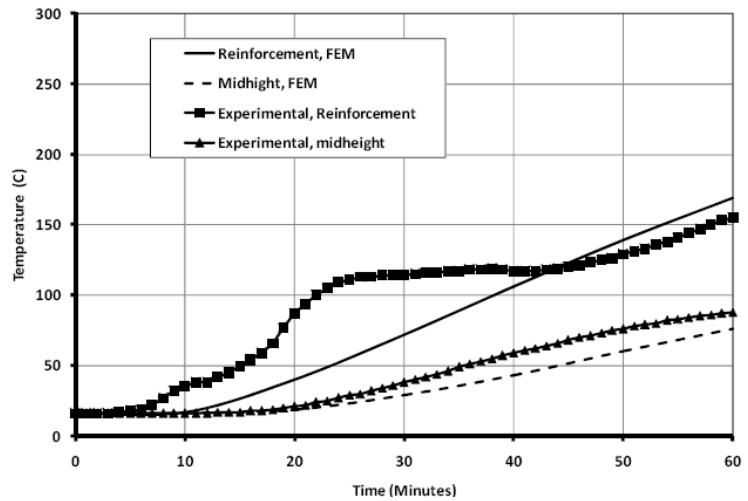

Fig. 16. Experimental and FEM temperatures at reinforcement \& mid depth of slabs tested under Hydrocarbon curve. 


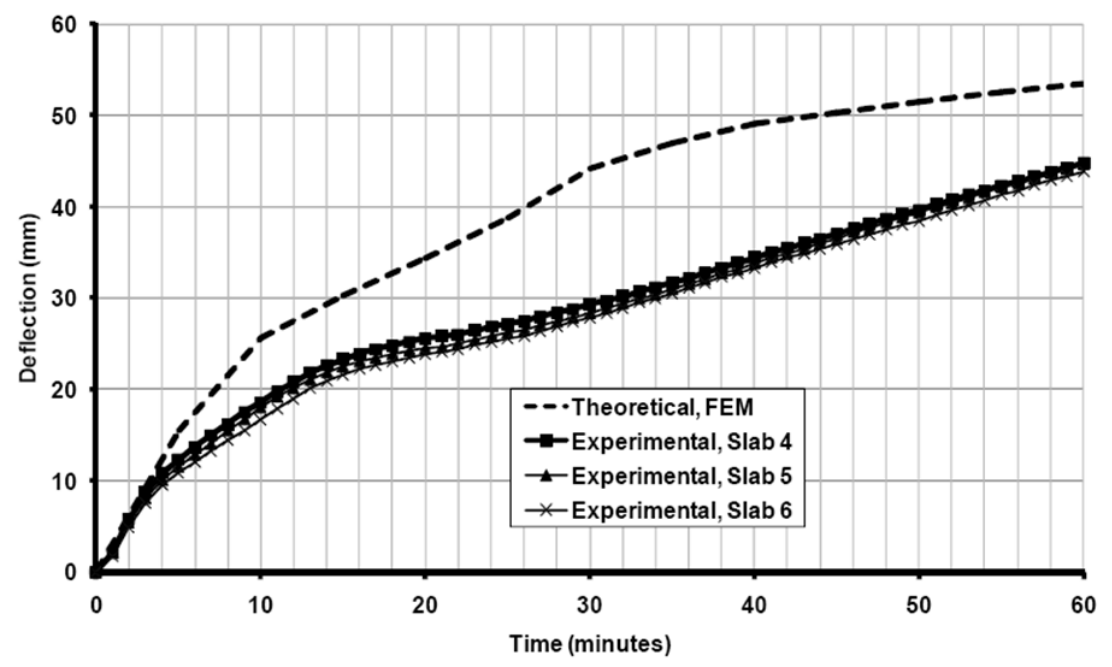

Fig. 17. Slab deflection obtained from Hydrocarbon fire tests and calculated using FEM

\section{CONCLUSIONS}

1. All the normal strength reinforced concrete slabs experienced explosive spalling, regardless of the heating regime utilized during the experiments.

2. An increase in fire severity resulted in earlier occurrences of explosive spalling, with slabs exposed to the hydrocarbon and BS476 fire curves experiencing explosive spalling after 2 and 15 minutes respectively.

3. It was noticed that all the normal strength reinforced concrete slabs exhibited a large thermal gradient between the slab surface, the steel reinforcement and the slab core.

4. Concrete slabs exposed to more severe fires experienced more rapid deflection rate.

5. Slabs exposed to the severe hydrocarbon fire have experienced a higher degree of explosive spalling; therefore lower heating rates minimized, but did not eliminate, the risk of explosive spalling.

6. From the tests undertaken, the actual depth of spalled slab parts was not noticeably affected by an increase in fire severity.

7. Hard evidence in the form of pictures, confirming the moisture clog movement away from the heated concrete face was obtained.

8. A Finite Element Model was built using DIANA software. The transient heat non linear structural calculations taking into account creep and cracking produced in some cases a reasonable agreement but also produced diverged results in other cases when compared with the experimental values.

9. It is recommended (where it is feasible) to use an experimentally obtained mechanical and thermal proprieties as an input parameters to numerical models to obtain more accurate analysis results.

\section{REFERENCES}

[1] Ali F. A., Nadjai A., Slikock G. Outcomes of a Major research on high strength concrete in Fire. Fire Safety Journal, Volume 39, Issue 6, September 2004, p 433-445. doi:10.1016/j.firesaf.2004.02.004

[2] Anderberg Y, Thelanderson S. A constitutive law for concrete at transient high temperatures conditions. ACI SP-55, 1977:187-205

[3] Buchanan HA. Structural design for fire safety. John Wiley Sons, England 2001. 
[4] Chung, J.H.; Consolazio, G.R. Numerical modeling of transport phenomena in reinforced concrete exposed to elevated temperatures. Cement and Concrete Research, v35, n 3, March, 2005, p 597608. doi:10.1016/j.cemconres.2004.05.037

[5] Cooke, G.M.E. Behaviour of precast concrete floor slabs exposed to standardised fires. Fire Safety Journal, v 36, n 5, July, 2001, p 459-475. doi:10.1016/S0379-7112(01)00005-4

[6] DIANA Finite Element Analysis, user manuals, TNO Building and Construction research., release 5. Delft, 2005.

[7] El-Hawary, M.M.; Ragab, A.M.; Osman, K.M., Abd El-Razak, M.M. Behavior investigation of concrete slabs subjected to high temperatures. Computers and Structures, v 61, n 2, Oct, 1996, p 345-360. doi:10.1016/0045-7949(96)00061-2.

[8] Eurocode 2. Design of Concrete Structures, part 1-2: general rules-structural fire design 2004.

[9] Gamal, A. Hurst, J. Modeling the thermal behavior of concrete slabs subjected to the ASTM E119 standard fire condition. Journal of Fire Protection Engineering, v 7, n 4, 1995, p 125-132.

[10] Huang, C.L.D, Gamal N.A. Influence of slab thickness on responses of concrete walls under fire Numerical Heat Transfer. International Journal of Computation and Methodology; Part A: Applications, v 19, n 1, Jan-Feb, 1991, p 43-64.

[11] Jensen, J.J.; Thorenfeldt, E.; Tomaszewicz, A. Structural properties of high-strength concrete and application in design Proceedings of the International Conference on Behavior of Offshore, 1988, p 1129

[12] Selih, J., Sousa, A.C.M.; Bremner, T.W. Moisture and heat flow in concrete walls exposed to fire. Journal of Engineering Mechanics, v 120, n 10, Oct, 1994, p 2028-2043.

[13] Shirley T., Burg R. G., Fiorato A. E. Fire Endurance Of High-Strength Concrete Slabs. ACI Materials Journal V.85, No. 2, March-April 1988, p 102-108.

[14] Shuttleworth P. Fire Protection of Concrete Tunnels Linings. The Third International Conference on Tunnel Fires and Escape from Tunnels, 9-11 October 2001, Washington DC, USA, p157165. 